\title{
Spontaneous rupture of a renal artery pseudoaneurysm in a previously hypertensive patient
}

\author{
Myung-Sung Kim, Young-Bae Lee, Jae-Hyuk Lee, Chae-Wan Lim, Jun-Hyoung Kim, Hye-Min Choi and Dong-Jin Oh*
}

\begin{abstract}
Previously, renal artery pseudoaneurysms were thought to be extremely uncommon. However, these lesions are now being detected more frequently as incidental findings on computed tomography, magnetic resonance imaging, and the extensive use of angiography. The incidence of ruptured renal artery pseudoaneurysms is very low. We report a case of a giant renal artery pseudoaneurysm (9.4-cm diameter) with severe left flank pain and a syncopal attack in a young woman who did not control high blood pressure for a couple of years.
\end{abstract}

Keywords: Hypertension, Renal artery, False aneurysm, Spontaneous rupture

\section{Background}

Renal artery pseudoaneurysm is a rare vascular lesion that arises when an arterial injury occurs within the kidney [1]. It is found with increasing frequency as a result of unrelated abdominal imaging or on work-up for hypertension [2]. While rarely symptomatic, it can be a cause of life-threatening hemorrhage and shock [3]. We describe a case of spontaneous rupture, definitely from a pseudoaneurysm of a renal arterial branch, presenting with massive retroperitoneal hemorrhage in a young woman who did not control high blood pressure for a couple of years.

\section{Case presentation}

A 32-year-old woman was admitted with a sudden onset of severe left flank pain. According to history taking, she was hypertensive for a couple of years. However, she did not perform any work-up to elucidate the etiology of high blood pressure. In addition, she did not take any antihypertensive medication despite a local clinic doctor's recommendation to control high blood pressure. She was not pregnant at admission. There were other specific past medical histories including trauma, renal surgery, percutaneous procedures, as well as inflammatory and neoplastic processes within the kidney. On

\footnotetext{
* Correspondence: intmdoh@hanmail.net

Department of Internal Medicine, Myongji Hospital, 55 Hwasu-ro 14 beon-gil, Deogyang-gu, Goyang 412-826, Korea
}

(c) 2015 Kim et al.; licensee BioMed Central. This is an Open Access article distributed under the terms of the Creative Commons Attribution License (http://creativecommons.org/licenses/by/4.0), which permits unrestricted use, distribution, and reproduction in any medium, provided the original work is properly credited. The Creative Commons Public Domain Dedication waiver (http://creativecommons.org/publicdomain/zero/1.0/) applies to the data made available in this article unless otherwise stated.

examination, the patient was in hypovolemic shock (systolic blood pressure, $80 \mathrm{mmHg}$; hemoglobin, $7.5 \mathrm{~g} / \mathrm{dL}$ ). The abdomen was diffusely tender, guarded, and distended, suggestive of an acute surgical condition. The computed tomography (CT) scan confirmed a large retroperitoneal hematoma from a giant (9.4-cm diameter) left renal artery pseudoaneurysm, which extended through a gap in the anterior renal fascia from a left perirenal hematoma (Figure 1). Active bleeding from the left renal artery pseudoaneurysm was detected at the time of the angiogram (Figure 2). So, we performed embolization using metal coils (Figure 3). The patient had no further episodes of bleeding. After the event, antihypertensive agents using a calcium channel blocker and angiotensin receptor blockade were prescribed to control high blood pressure. Now her blood pressure and renal function are normal.

\section{Discussion}

Renal artery aneurysms including pseudoaneurysms (RAAs) are localized dilations of the renal artery and/or branches. Although rare, there has been a recent increase in the discovery of renal arteriovenous fistulas secondary to trauma, inflammation, renal surgery, and percutaneous needle biopsy [4]. However, more recent literature has demonstrated that the overall incidence ranges between $0.01 \%$ and $1 \%[4,5]$. This increases to $2.5 \%$ when only patients with hypertension are considered [5] and can be as high as $39 \%$ in patients with 


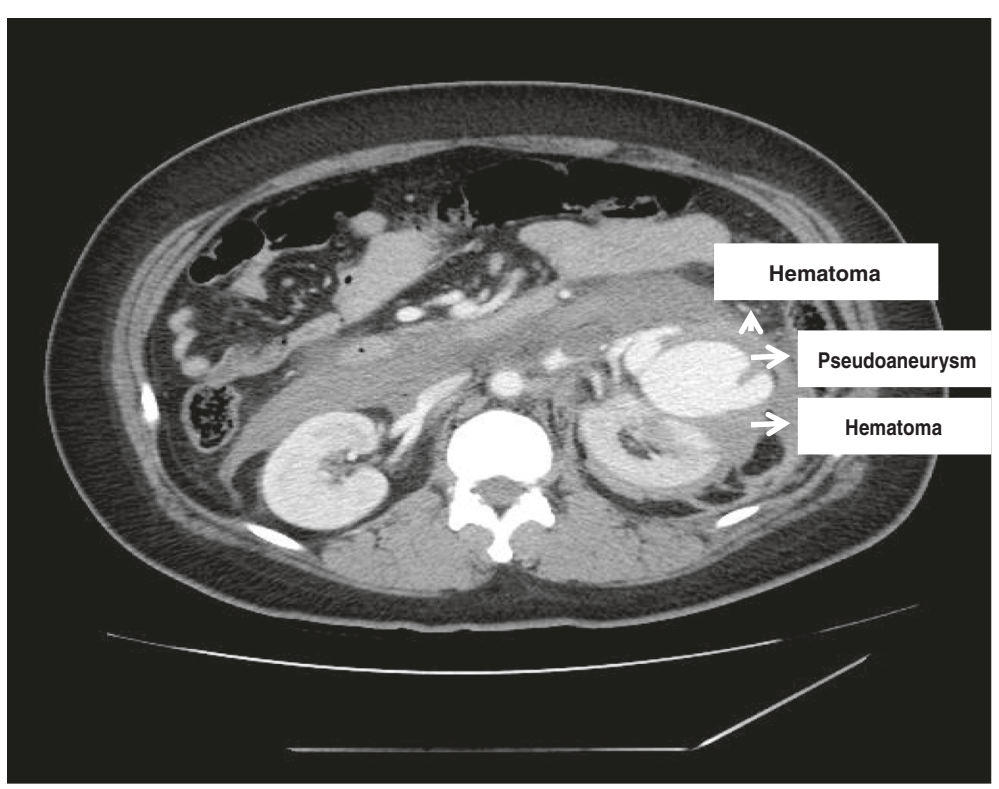

Figure 1 Computed tomography scan confirmed a large retroperitoneal hematoma from a left renal artery pseudoaneurysm, which extended through a gap in the anterior renal fascia from a left perirenal hematoma.

hypertension unresponsive to medical therapy [6,7]. The mean age at diagnosis is 60 years. RAAs occur more commonly in men and are primarily located on the right [8]. RAAs can be either congenital or acquired. Congenital RAAs have been associated with autosomal dominant polycystic disease, fibromuscular dysplasia, and tuberous sclerosis [9]. Acquired etiologies include long-standing untreated hypertension, atherosclerosis,

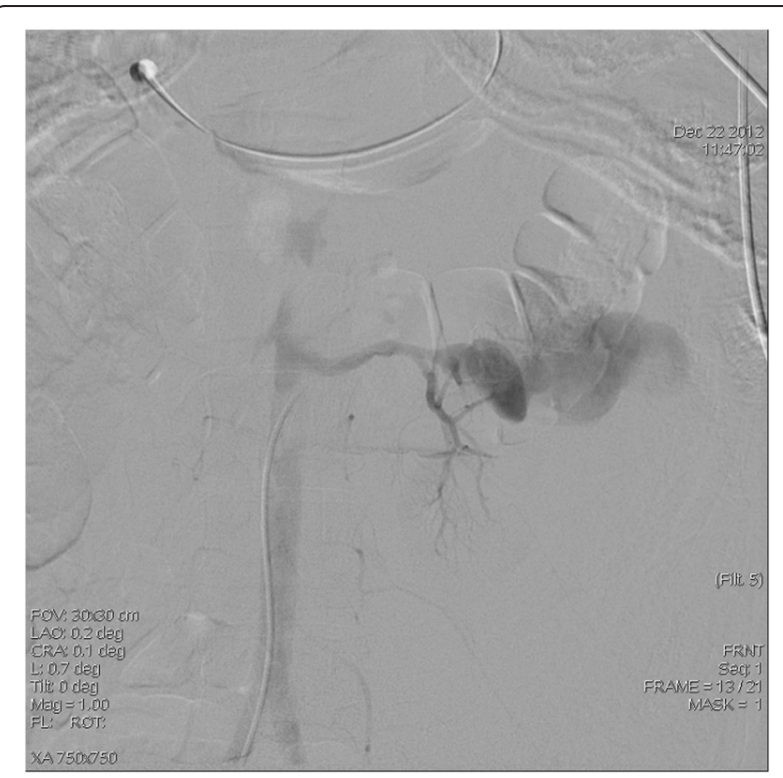

Figure 2 Left renal angiography showed a pseudoaneurysm on a branch of the left renal artery. Active bleeding was detected at the time of the angiogram. blunt $[4,10]$ and penetrating trauma, recent surgical manipulation (open, laparoscopic, and/or endovascular) [11], infectious angiomyolipomas (i.e., mycotic) [12], polyarteritis nodosa [8], malignancy, coagulopathy, radiation, and/or cyclophosphamide use [8]. The risk of rupture is thought to vary inversely with size, and most investigators agree that an aneurysm exceeding $2 \mathrm{~cm}$ is more likely to undergo rupture. Most RAAs are discovered on a work-up for hypertension (55\%) and are more frequently being discovered incidentally during unrelated abdominal imaging (i.e., radiography, color Doppler ultrasound, CT, and magnetic resonance [MR] imaging or angiography) [4]. Although angiography is the gold standard, perhaps the best noninvasive test to evaluate location, size, structure, and relation to nearby organs is CT/MR angiography [8]. When patients present with symptoms, they are usually flank pain and hematuria that can range from mild microscopic hematuria to gross hemorrhage leading to hemodynamic instability [13].

Indications for treatment include hemorrhage, uncontrolled hypertension, pain, progressive enlargement, presence of an arteriovenous fistula, with size $>2$ to $2.5 \mathrm{~cm}$ or size $>1 \mathrm{~cm}$ in a female of childbearing age [14]. Currently, endovascular surgery is the intervention of choice in elective or emergent circumstances. Accepted endovascular treatments include embolization (i.e., gelfoam, coils, alcohol) or stenting across the aneurysm [15]. There have also been case reports of successful management of RAAs with percutaneous thrombin injection directly into the aneurysm. Factors that may preclude endovascular management are size and multiplicity, although there have 


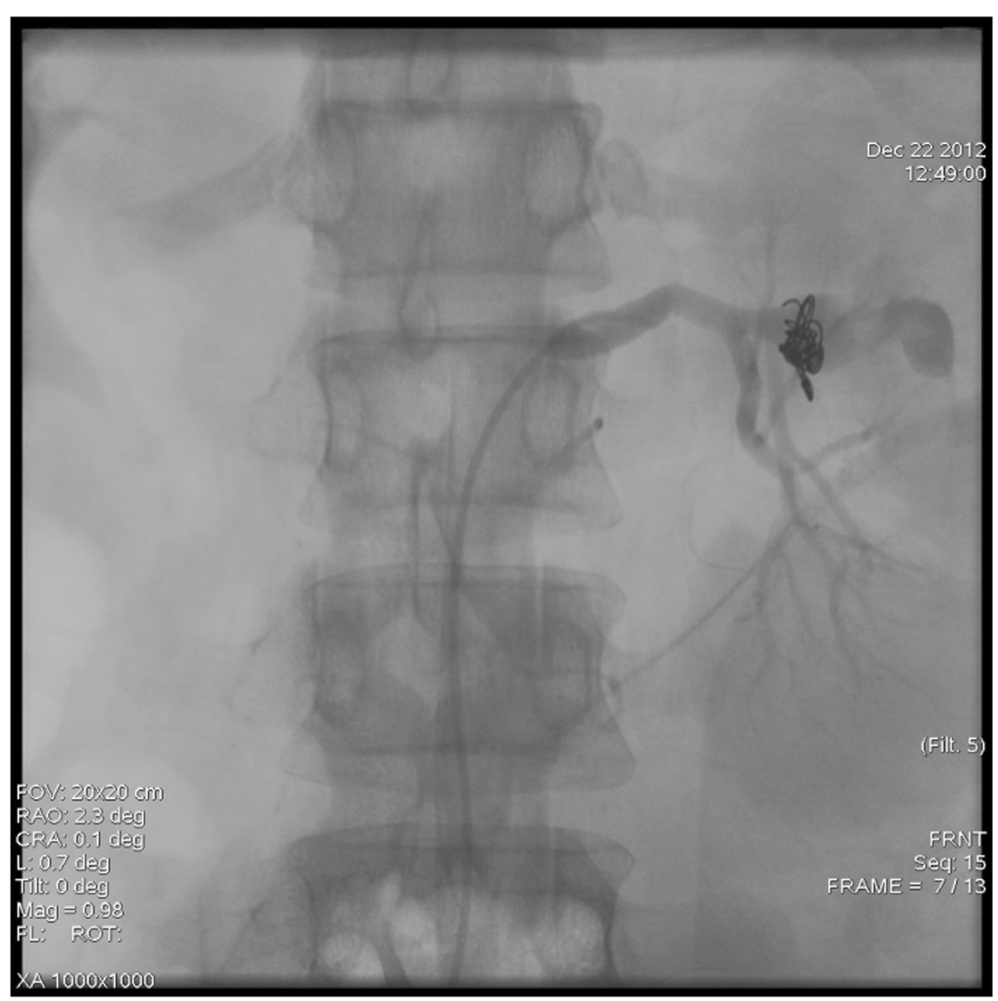

Figure 3 Embolization was performed using metal coils.

been reports of successful endovascular management of large $(10 \mathrm{~cm})$ RAAs endovascularly [15], like our case and another case in Korea [16].

\section{Conclusion}

We report a case of a giant renal artery pseudoaneurysm (9.4-cm diameter) with severe left flank pain and a syncopal attack in a young woman who did not control high blood pressure for a couple of years. Therefore, we would like to emphasize the importance of high blood pressure control and the necessity of work-up to elucidate the etiology of high blood pressure especially in patients with newly developed hypertension.

\section{Consent}

Written informed consent was obtained from the patient for publication of this case report and any accompanying images. A copy of the written consent is available for review by the Editor-in-Chief of this journal.

\section{Abbreviations}

CT: Computed tomography; RAAs: Renal artery aneurysms including pseudoaneurysms; MR: Magnetic resonance.

\section{Competing interests}

The authors declare that they have no competing interests.

\section{Authors' contributions}

MSK wrote the manuscript. YBL collected the CT data. JHL collected the renal angiography data. CWL assisted in the coil embolization. JHK examined the patient physically and explained the procedure to her. HMC assisted in the revision of our manuscript. DJO carried out the review and correction. All authors read and approved the final manuscript.

Received: 21 October 2014 Accepted: 5 December 2014 Published online: 31 January 2015

\section{References}

1. Ngo TC, Lee JJ, Gonzalgo ML. Renal pseudoaneurysm: an overview. Nat Rev Urol. 2010;7:619-25.

2. Bulbul MA, Farrow GA. Renal artery aneurysms. Urology. 1992;40:124-6.

3. Fraser GE, Poncia H. Spontaneous renal artery aneurysm rupture: an unusual cause of abdominal pain and syncope. Emerg Med J. 2009;26:619-20.

4. Giannopoulos A, Manousakas T, Alexopoulou E, Brountzos E, Papadoukakis $\mathrm{S}$, Kelekis D. Delayed life-threatening haematuria from a renal pseudoaneurysm caused by blunt renal trauma treated with selective embolization. Urol Int. 2004;72:352-4.

5. Porcaro AB, Migliorini F, Pianon R, Antoniolli SZ, Furlan F, De Biase V, et al. Intraparenchymal renal artery aneurysms: case report with review and update of the literature. Int Urol Nephrol. 2004;36:409-16.

6. De Wilde V, Devue K, Vandenbroucke F, Breucq C, De Maeseneer M, De Mey J. Rupture of renal artery aneurysm into the renal pelvis, clinically mimicking renal colic: diagnosis with multidetector $\mathrm{CT}$. Br J Radiol. 2007;80:e262-4.

7. Park J. Middle aortic syndrome with superior mesenteric and bilateral renal artery involvement: unusual type of aortic coarctation. J Korean Soc Hypertens. 2013;19:39-43.

8. Glass PM, Uson AC. Aneurysms of the renal artery: a study of 20 cases. J Urol. 1967;98:285-92.

9. Tham G, Ekelund L, Herrlin K, Lindstedt EL, Olin T, Bergentz SE. Renal artery aneurysms. Natural history and prognosis. Ann Surg. 1983;197:348-52. 
10. Lindekleiv H, Haro S, Nordhus K, Eggen T, Due J. Renal artery pseudoaneurysm secondary to blunt trauma nine years earlier: case report and review of the literature. Scand J Urol Nephrol. 2008;42:488-91.

11. Gupta V, Galwa R, Khandelwal N, Bapuraj JR. Postpyelolithotomy renal artery pseudoaneurysm management with percutaneous thrombin injection: a case report. Cardiovasc Intervent Radiol. 2008;31:422-6.

12. Ohebshalom MM, Tash JA, Coll D, Su LM, Schlegel PN. Massive hematuria due to right renal artery mycotic pseudoaneurysm in a patient with subacute bacterial endocarditis. Urology. 2001;58:607.

13. Dulabon LM, Singh A, Vogel F, Moinzadeh A. Intrarenal pseudoaneurysm presenting with microscopic hematuria and right flank pain. Can J Urol. 2007;14:3588-91.

14. Hughes JH, Stanisic TH, Buster D, Nagle RB. Massive nontraumatic hematuria: a challenge demanding immediate action. Postgrad Med. 1980:67:97-106.

15. Ishizuka O, Takayama F, Sone S. Large renal aneurysm successfully treated by percutaneous embolization using detachable steel coils. Int J Urol. 2006;13:993-4

16. Park JW, Han JH, Kim MS, Lim HG, Chung SJ, Kim JH, et al. A case of renal artery aneurysm treated with a covered stent-graft. J Korean Soc Hypertens. 2010;16:30-4.

\section{Submit your next manuscript to BioMed Central and take full advantage of:}

- Convenient online submission

- Thorough peer review

- No space constraints or color figure charges

- Immediate publication on acceptance

- Inclusion in PubMed, CAS, Scopus and Google Scholar

- Research which is freely available for redistribution 